Conference abstract PPAT10

\title{
Use of Forced Degradation Studies on S-(-)-Amlodipine Besylate to Generate Information on the Degradation Products
}

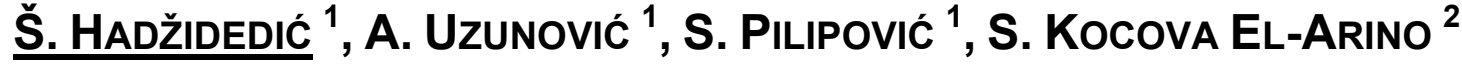 \\ ${ }^{1}$ Agency for Medicinal Products and Medical Devices of B\&H, 71000 Sarajevo, Bosnia and Herzegovina \\ ${ }^{2}$ National Research Centre, Tahrir Street, Cairo, Egypt \\ E-mail: s.hadzidedic@alims.gov.ba (S. Hadžidedić)
}

Sci Pharm. 2010; 78: 699

doi:10.3797/scipharm.cespt.8.PPAT10

\begin{abstract}
Amlodipine is a long-acting calcium channel blocker used in the treatment of hypertension and angina pectoris. $S$-(-)-amlodipine besylate is a safer and longer-acting alternative to the existing racemate [1]. Although several products based on the active enantiomer have reached the market, information on its chemical, physical and thermal stability during storage is lacking [2,3]. The objective of the present study was to evaluate the critical properties of the S-enantiomer and to obtain information on the degradation pathways during storage of the bulk drug. The degradation products formed upon subjecting $S$-(-)-amlodipine besylate to different conditions (hydrolysis, oxidation, high and low $\mathrm{pH}$, dry heat and photolysis) were resolved on a Lichrospher RP-18 column using $237 \mathrm{~nm}$ as detection wavelength [4,5]. A good understanding of the chemical and physical stability of the drug was gained based on the results of the forced degradation study.

Acknowledgements: This work was supported by ALIMS B\&H.
\end{abstract}

[1] Hutt AJ, Valentova J. The Chiral Switch:The Development of Single Enantiomer Drugs from Racemates. Acta Facultatis Pharmaceuticae Universitatis Comenianae. 2003; 50: 7-23.

[2] EMEA Guideline, Guideline on Impurities in New Medical Products, (CPMP/ICH/282/95), 1995, 1/14.

[3] Li ZJ, Zell MT, Munson EJ, Grant DJ. Characterization of racemic species of chiral drugs using thermal analysis, thermodynamic calculation, and structural studies. J Pharm Sci. 1999; 88: 337-346. doi:10.1021/js980205u

[4] Abdoh A, Al-Omari MM, Badwan AA, Jaber AMY. Amlodipine Besylate-Excipients Interaction in Solid Dosage Form. Pharm Dev Technol. 2004; 9: 1-10. PMid:15000463

[5] Giron D. Characterization of salts of drug substances. J Therm Anal Calorim. 2003; 73: 441-457. doi:10.1023/A:1025461625782 